\title{
Cost-effectiveness of total laparoscopic hysterectomy and non-descent vaginal hysterectomy versus total abdominal hysterectomy: a multi-centre randomized controlled trial
}

Chanil Deshan Ekanayake ( $\square$ cdekanayake2000@yahoo.co.uk)

District General Hospital-Mannar https://orcid.org/0000-0001-5662-155X

Arunasalam Pathmeswaran

University of Kelaniya Faculty of Medicine

Sanjeewa Kularatna

Queensland University of Technology

Rasika Herath

University of Kelaniya Faculty of Medicine

Prasantha Wijesinghe

University of Kelaniya Faculty of Medicine

\section{Research Article}

Keywords: Non-descent vaginal hysterectomy, total laparoscopic hysterectomy, total abdominal hysterectomy, cost-effectiveness, randomized controlled trial

Posted Date: February 4th, 2019

DOI: https://doi.org/10.21203/rs.2.279/v1

License: (c) (1) This work is licensed under a Creative Commons Attribution 4.0 International License.

Read Full License 


\section{Abstract}

Background: Hysterectomy is the most common major surgical procedure in gynaecology. The methods in mainstream practice are; total abdominal hysterectomy (TAH), non-descent vaginal hysterectomy (NDVH) and total laparoscopic hysterectomy (TLH). Most patients requiring hysterectomy for benign gynaecological conditions can be operated using one of these methods. The aim of this study was to study cost-effectiveness of NDVH, TLH and TAH in a low resource setting.

Methods: A pragmatic multi-centre three arm (parallel groups) RCT was done in the professorial gynaecology unit of the North Colombo Teaching Hospital, Ragama and the gynaecology unit of the District General Hospital, Mannar, Sri Lanka. Participants were patients requiring hysterectomy for nonmalignant uterine causes. Exclusion criteria were uterus $>14$ weeks, previous pelvic surgery, medical illnesses which contraindicate laparoscopic surgery, and those requiring incontinence surgery or pelvic floor surgery. The main outcome measures were time to recover and cost. The willingness-to-pay (WTP) threshold was set at USD 1000.

Results: There was no significant difference in median time to recover (inter quartile range) among TAH, NDVH and TLH which was 35 (30-45), $32(24.5-60)$ and 30 (25.5-45) days respectively $(p=0.37)$. The difference in area under the curve for quality adjusted life years (QALYs) was 1.33 and 5.21 for NDVH and TLH compared to TAH. The direct cost (median, interquartile range) of a TLH [USD 349 (322-378)] was significantly higher compared to TAH [USD 289 (264-307)] and NDVH [USD 279 (255-305)]. The incremental cost-effectiveness ratio (ICER) for TLH was USD 12/day whereas NDVH showed a net benefit as both costs and median effect were superior to TAH. The incremental cost utility ratio (ICUR) for TLH and NDVH were 12 and 38 USD/QALY. The ICUR for TLH compared to NDVH was USD 3/per QALY. The net monetary benefit (NMB) was USD 4897 and USD 1264 for TLH and NDVH respectively.

Conclusion: Despite there being only a marginal difference among the three routes when considering time to recover, a cost-effectiveness approach using ICER, ICUR and NMB shows that alternate routes, NDVH and TLH to be superior to the conventional TAH.

Trial Registration: Sri Lanka clinical trials registry, SLCTR/2016/020 and the International Clinical Trials Registry Platform, U1111-1194-8422, on 26 July 2016. Available from: http://slctr.lk/trials/515.

Keywords: Non-descent vaginal hysterectomy, total laparoscopic hysterectomy, total abdominal hysterectomy, cost-effectiveness, randomized controlled trial.

\section{Background}

Hysterectomy is the commonest major gynaecological procedure [1-3]. Hysterectomy rates in lowresource settings such as Sri Lanka can be assumed to be high due to the non-availability of alternative methods like levonorgestrel intrauterine system (LNG-IUS), endometrial ablation and adequate resources 
in out-patient settings to follow up patients on medical therapy. As a result a significant proportion of these women who could have been managed with these methods also undergo hysterectomy.

The route of hysterectomy will depend on the pathological nature, uterine size, uterine descent, presence of endometriosis and the likelihood of pelvic adhesions and adnexal masses, previous pelvic surgery, surgeon's preference and patient's request [4]. Although there are many approaches to pelvic surgery the methods in mainstream practice are; total abdominal hysterectomy (TAH), non-descent vaginal hysterectomy (NDVH) and total laparoscopic hysterectomy (TLH).

In some instances the most appropriate route is obvious; e.g., if the uterus is larger than 20-weeks, a total abdominal hysterectomy (TAH) may be the method of choice. While in malignancy a more radical approach with other additional surgical procedures would be needed. In uterine prolapse, with coexistent cystocele or rectocele a vaginal hysterectomy and repair would be the best approach to handle all the problems. Therefore the route is obvious in these instances.

However there is a group of benign gynaecological conditions where the uterus is less than 14-weeks with no descent for which, any one of the three main methods of hysterectomy can be applied. Therefore it is worth finding out the cost-effective method of hysterectomy among these three routes especially in lowresource settings where alternate methods of management like LNG-IUS, endometrial ablation are not available.

When considering surgical methods, most comparisons are between two methods, abdominal versus laparoscopy, with little information on NDVH except a few studies from low resource settings [5-8]. There is also a paucity of evidence on RCTs in low resource settings especially when considering costeffectiveness.

Therefore the aim of this study was to seek evidence on the most appropriate route of hysterectomy in terms of cost-effectiveness by way of a three arm randomized controlled trial (RCT) between NDVH, TLH and $\mathrm{TAH}$ in a low resource setting.

\section{Methods}

The detailed study protocol was published earlier (4). The period of study was six months from the date of surgery for the economic evaluation.

\section{Design, setting and participants}

A pragmatic multi-centre three arm (parallel groups) RCT was done in accordance to Consolidated Standards of Reporting Trials (CONSORT) (additional file 1) [9]. The economic evaluation was done according to the CHEERS checklist (additional file 2) [10]. The study was done in the professorial gynaecology unit of the North Colombo Teaching Hospital, Ragama and the gynaecology unit of the District General Hospital, Mannar, Sri Lanka. Eligible participants were patients requiring hysterectomy for non-malignant uterine causes. Exclusion criteria was uterus $>14$ weeks, previous pelvic surgery, any 
medical illness which caution/contraindicate laparoscopic surgery, and those requiring incontinence surgery or pelvic floor surgery. Eligible patients were aware that they would be randomly assigned to undergo one of the three procedures. The main exposure variables were NDVH and TLH. The control group consisted of patients undergoing TAH (see Fig. 1). Standard techniques of TLH, TAH and NDVH was followed and the decision to convert to laparotomy at TLH or NDVH was at the discretion of the primary surgeon $[11,12]$.

\section{Sample size calculation}

A difference of seven days was considered as clinically significant based on a study published in the BJOG by Ottosen et al [13]. A sample size of 49 patients per arm was required considering a type I error of 0.01 and a power of $80 \%$ and with a possible loss to follow up rate of $20 \%$ to detect a seven day difference between the three types; TLH versus TAH versus NDVH. The reason for a type 1 error of 0.01 (two-sided) was for a Bonferroni adjustment for multiplicity to keep the overall $p$ value to less than 0.05 after pairwise comparisons.

\section{Randomization}

Block randomization in multiples of three was done at each study site by opening sealed envelopes containing computer-generated block randomization numbers, with block sizes of six and nine to ensure roughly equal numbers of patients in each arm at any point in the study. The patients and medical team were not blinded to the intervention.

\section{Outcome measures}

The primary outcome measure was time to recover following hysterectomy (earliest time to resume all or a combination of activities done prior to surgery; resumption of cooking, washing clothes, sexual activity and occupation). The secondary outcomes were operative time, time under anaesthesia, post-operative hospital stay, blood loss, pain scores, complications, quality adjusted life years (QALYs) and cost per procedure (direct hospital related costs and indirect patient borne costs).

Complications were graded and converted to an ordinal scale as follows; no complication (1), postoperative fever (2), skin wound infection (2), urinary tract infection (2), blood transfusion (2), laparotomy (3), bowel damage (4), bladder injury (4), ureteric injury (4), fistulae (4). If a patient had more than one complication the total score of all the complications were taken.

Quality Adjusted Life Years (QALYs) were estimated based on the EuroQol-Five Dimension Three Level (EQ-5D-3L) Questionnaire sequentially at pre-operative baseline, post-operative day two, seven, 6-weeks, 3-months and 6-months [14]. The EQ-5D-3L is a generic patient reported outcome measurement tool on health-related quality of life with five dimensions (mobility, self-care, usual activities, pain/discomfort, and anxiety/depression) and three self-rated response levels of severity (e.g. no problem, some problem, major problem) for each dimension. Sri Lankan EQ-5D-3L weights were applied to estimate utility values at each of these time points [15]. Within trial QALYs were calculated for each route (TAH, NDVH and TLH) 
using area under the curve (AUC) estimated by integral calculation for each of the follow-up periods respectively.

\section{Data analysis}

All patients were included in the analyses. Data analysis was based on the intention-to-treat principle. A Kaplan Meier survival analysis was done for the primary outcome which is time to recover following hysterectomy. The end-point was the actual time to recover. Post hoc pairwise comparison between TAH, NDVH and TLH was done using COX regression. The other outcomes; operative time, anaesthesia time, post-operative hospital stay, cost, pain scores and blood loss were analysed using Kruskal-Wallis test with post hoc comparisons. A fully specified statistical analysis plan and database is provided (additional files 3 and 4).

\section{Economic evaluation}

The economic evaluation took a societal perspective and included direct costs related to utilization of healthcare resources in the hospital and indirect costs borne by the patient. A micro-costing approach was adopted to calculate utilization of hospital resources from the time of presentation to the gynaecology clinic up to six months after surgery. A detailed explanation of the methodology used in calculating costs was also published [16].

The incremental cost-effectiveness ratio (ICER) was estimated using median cost for the intervention arms (TLH or NDVH) minus the median cost for the standard treatment (TAH) arm divided by the median time to recover of the intervention arms (TLH or NDVH) minus the median time to recover of the standard treatment (TAH) arm. The ICER for the worst case scenario was calculated using third quartile (Q3) of time to recover and costs of the intervention arms (TLH and NDVH) versus the standard treatment (TAH). The ICER for the best case scenario was calculated using first quartile (Q1) of time to recover and costs of the intervention arms (TLH and NDVH) versus the standard treatment (TAH).

The incremental cost-utility ratio (ICUR) was estimated using mean direct cost for the intervention arm (TLH or NDVH) minus the mean direct cost for the standard treatment arm (TAH) divided by the QALYs of the intervention arm (TLH or NDVH) minus the QALYs of the standard treatment arm (TAH). The willingness to pay (WTP) threshold was considered to be $25 \%$ of the GDP per capita income [17]. Therefore a lower estimate of USD 1000 was considered based on the GDP per capita income of USD 4065 for the year 2017 [18]. The net monetary benefit (NMB) was considered as the incremental QALYs multiplied by the WTP threshold minus the mean incremental costs of the intervention group compared to the standard management group.

All cases were included in the analysis as there was a likelihood of either overestimating or underestimating costs if an uncomplicated or a complicated case was excluded. Missing data was not excluded and multiple imputation was used for missing data which was less than $5 \%$. The costs are reported in USD (Exchange rate, 1 USD= LKR. 144.9625, as at 01/01/2017). 
A deterministic sensitivity analysis was done to assess the robustness of costing assumptions. The worst case scenario considered a 5-year shelf life for surgical instruments, an additional 30 minutes of operating time, an additional post-operative day, doubling of the cost of complications and readmissions, doubling of utility costs and discounting rate of $10 \%$ using a standard discount table [19]. The best case scenario considered a 5-year shelf life for surgical instruments, 30 minutes less of operating time, a hospital stay of one day less post-operatively, with no complications and readmissions, and discounting rate of $10 \%$.

\section{Results}

The participant flow diagram is shown in Fig. 1. Out of the 147 patients, 71 (TAH-24, NDVH-23 and TLH24) was from Mannar whilst 76 (TAH-25, NDVH-26, and TLH-25) were from Ragama. Over one years' of follow-up, 139 patients out of 147 completed the entire follow-up. In the TAH arm, two patients from Mannar were lost to follow-up after 6-months as they moved to a different location. In the TLH arm, two patients from Mannar (one after 6-weeks and another after 6-months) were lost to follow-up for similar reasons. In the NDVH arm, two patients from Mannar were lost to follow-up after 3-months and 6-months respectively, whilst from Ragama, one patient died following a myocardial infarction after 6-months and another was followed up at a different hospital from 6-months onwards. The basic characteristics of the three groups; TAH, NDVH and TLH were similar in terms of age, BMI, parity and uterine weight (Table 1).

The time to recover is shown by a Kaplan-Meier plot in Figure 02. There was no difference in median time (interquartile range) to recover among TAH, NDVH and TLH which was 35 (30-45), 32 (24.5-60) and 30 (25.5-45) days respectively ( $p=0.37$, Table 2$)$.

The time under anaesthesia and operative time were significantly more in the TLH group compared to TAH and NDVH groups (Table 2. Kruskal Wallis test, $p<0.001$ ). However the post-operative hospital stay was shorter in the TLH group with a median stay of two days compared to three days for TAH and NDVH groups (Table 02. Kruskal Wallis test, $p<0.001$ ). There was no significant difference in operative blood loss or a change in haematocrit (difference between pre-op and post-op). The pain scores on day one and two were significantly lower in the TLH group compared to TAH and NDVH groups (Kruskal Wallis test, $\mathrm{p}<0.01)$.

In terms of major complications, three patients in the NDVH group needed subsequent laparotomies (two due to bladder injuries and one due to internal bleeding). There was also one rectal injury. In the TLH group there were two laparotomies and one ureteric injury. The ureteric injury in TLH and one of the bladder Injuries in NDVH led to an uretero-vaginal fistula and a vesico-vaginal fistula respectively which resulted in the extreme outliers in the time to recover for the TLH and NDVH arms (Fig. 2).

Cox regression for analysis of covariates showed that the severity of complications (for one increase in complications scoring, a $25 \%$ increase in time to recover, $p=0.04$ ) was significantly associated with time to recover. However age $(p=0.86), B M I(p=0.29)$, parity $(p=0.87)$, operative time $(p=0.52)$, change in haematocrit $(p=0.68)$, day one pain scores $(p=0.74)$, day two pain scores $(p=0.76)$ or post-operative 
hospital stay $(p=0.85)$ did not have a significant effect on time to recover (additional file 5$)$. The effect of these factors on each individual route are also shown in additional file 5. At Mannar a faster time to recover was observed for NDVH and TLH (NDVH had a $67 \%$ faster time to recover, $\mathrm{p}<0.01$ and TLH had a $66 \%$ faster time to recover, $p<0.01$ ) compared to Ragama.

The area under the curves (AUC) at the end of 6-months for TAH, NDVH and TLH were 8.63, 9.97 and 13.84 respectively (Fig. 3 and Table 3 ). The actual direct and total costs of a TLH were significantly higher compared to TAH and NDVH (Table 03. $p<0.001$ ). There was no significant difference in indirect costs among the three routes. The worst case scenario and best case scenario did not produce a significant difference among the three routes $(p=0.06$ and $p=0.03$, Table 3 , additional file 6$)$.

The incremental cost-effectiveness ratio (ICER) for NDVH showed a net benefit as costs and median effect were both better than the standard TAH (Table 4). ICER for TLH was USD 12/day (Table 4). The ICER for worst case scenario showed lower costs and a longer time to recover for NDVH which resulted in a poorer result than the conventional treatment, TAH. The ICER (worst case scenario) for TLH was infinite as there was no difference in third quartile (Q3) of time to recover between TLH and TAH, in addition to having higher costs for Q3. The ICER for best case scenario showed a net benefit for NDVH as time to recover and costs were both superior to TAH. ICER (best case scenario) for TLH was USD 24/day (Table 4).

\section{Discussion}

There was only a marginal difference in time to recover between the three routes which was not significant as the study was only powered to detect difference of seven days or more. However there was a considerable difference in the AUC for QALYs. In terms of costs, TLH costs significantly more than TAH and NDVH owing to higher equipment costs and longer operating times as previously reported [16]. In terms of ICER, TAH is dominant only in the worst case scenario and the alternate routes (NDVH and TLH) are superior in both the study setting and the best case scenario.

The exact WTP threshold per QALY has not been calculated in most low resource settings, and as such the WHO recommends a value of 1-3 times the GDP per capita income [20,21]. However even this is considered too high as it was shown that cost-effectiveness thresholds ranged from $4-51 \%$ of the GDP per capita income for low-middle income countries [17]. Therefore an estimate of $25 \%$ GDP per capita income was taken which is further corroborated by the calculating the opportunity costs based on minimum daily wage (Rs. $400 \times 365$ days = Rs. 146,000, 1 USD = Rs. 144.9625) [22]. However even considering this estimate the ICUR was below WTP threshold for both TLH and NDVH. Therefore TLH and NDVH can be considered cost-effective, or "acceptable value for money". The NMB for all three scenarios; study result, worst case and best case also show that TLH and NDVH have a net monetary gain compared to TAH. There is little change in ICER, ICUR and NMB even if Q1, Q3, mean or median are interchanged as the denominator. Similarly the change is minimal even if the lower limit or upper limit of 
the $95 \%$ confidence interval are substituted for the mean (numerator) which further strengthens the validity of our findings.

An important aspect that was found was that none of the covariates, age, BMI and parity or even more plausible variables like operative time, blood loss, pain score or post-operative hospital stay were significantly related to the time to recover. What was found was that the severity of complications, the centre and the surgeon affected the outcome which suggests that individual surgical technique had a stronger impact on the recovery than patient factors and indirect operative outcome measures. This suggests what is blatantly obvious in surgery, that meticulous surgical technique also needs due recognition whilst trying to optimize patient factors and indirect factors".

A differential expertise bias would have applied in this trial in favour of TAH because despite being competent in all three routes, the competency for TAH may be higher than the alternatives, despite being above the minimum stipulated standards to participate in the trial. This is because of the unique nature of training in Sri Lanka where competency for open surgery is acquired first prior to embarking on minimally invasive surgery. Although this may be a limitation in a developed setting where the ideal would be an expertise-based RCT, it may not be feasible to do the latter in most low resource settings like Sri Lanka.

When measuring the effect, QALYs were not considered as the primary outcome measure as the sample size would be impractical. Furthermore, it would have also not been realistic as it requires patients to assign themselves to a particular health state which may be inaccurate or partial and not match societal preferences $[19,23]$. Although disability-adjusted life-years (DALYs) were developed by the World Bank and World Health Organization (WHO) as part of a programme to estimate the global burden of disease, it's use in cost-effectiveness analysis has been limited due to issues pertaining to calculating disability weights and use of age-weights $[19,23]$. The time to recover although subjective, mimics the real-life scenario and is actually what a patient would be looking at, to return to normal activity as soon as possible.

Furthermore economic evaluation is concerned with the estimation of effect size and forecasting the degree of uncertainty using sensitivity analysis instead of hypothesis testing which is used in pure clinical research. The distribution of costs and effects can be significant even if the difference in costs and effects are not individually significant [24]. These reasons alleviate the need for sample size calculations in economic evaluation.

There were two NDVH cases and another two TLH cases which were converted to laparotomy. Although intention to treat analyses is an integral hallmark of clinical trials there have been concerns raised against it as some cases actually have a different treatment which accounts for the clinical effect in the allocated arm $[25,26]$. Procedure-wise analysis can overcome this issue if it significantly affects the outcomes and conclusions of the clinical trial. However this was not needed in our study as we considered the median statistic instead of the mean which abated impact of outliers. 
In terms of cost measurement, there were limitations due to assumptions that had to be adopted to overcome financial and logistical limitations in a low resource setting [16]. When calculating equipment costs for a particular surgery, the average rate of utilization was considered as there was no information about the duration of all procedures. Quantifying utility costs were also a problem as utilization of resources vary according to speciality and clinical problem. This problem was overcome by apportioning the costs for basic utilities using the average number of in-patients for the entire hospital assuming that each in-patient would consume a similar proportion of basic utilities. The cost of basic utilities during surgery was also likely to be reflected in the utility cost calculated using in-patient totals and as such was not done separately. The cost of theatre space was not considered assuming the duration of theatre time to be insignificant compared to total hospital stay. However in an ideal setting with modern theatres these costs should not be disregarded as they can be significant.

The training costs were not considered as training 'per se' is not exclusive in the Sri Lankan public medical sector where a mandatory service component is a must and as such it is difficult to separate the proportion of the cost of training. Furthermore training costs should be apportioned throughout a professional's career which will further lower initial training costs. The cost of documentation (hospital records, investigation forms and other stationery) was not considered. Discounting and adjustment for inflation was also not necessary as duration of the study was approximately two years [23].

The fact that our trial was a pragmatic trial improved the generalisability and external validity of our study results as this design incorporates human factors such as beliefs, effort and optimism etc into the estimate of effectiveness which mimics the ground reality in usual care settings $[9,19]$. The analytic perspective for costs in this study considered a societal perspective which is widely regarded in health economics to be the most accurate as transference of health costs are negated [23].

As NDVH and TLH are more cost-effective than TAH it suggests a change in attitude of gynaecologists, resource allocation from the Ministry of Health and even Post-graduate training to lay more emphasis on alternative routes of hysterectomy.

Sri Lanka is a low resource setting, and as such it is important for us to enquire in to cost-effectiveness to ensure that maximum value for money is obtained with the limited resources at hand. As this study was an RCT it provides level 1 evidence for the three main routes of hysterectomy and will establish a quantifiable and reproducible method of accessing surgical outcomes.

\section{Conclusions}

Despite there being only a marginal difference among the three routes when considering time to recover, a cost-effectiveness approach that considered both costs and effect using ICER, ICUR and INMB all show that alternate routes, NDVH and TLH to be superior to the conventional TAH.

\section{Abbreviations}


AUC, area under curve; EQ-5D-3L, EuroQoL group questionnaire on health related quality of life; ICER, incremental cost-effectiveness ratio; INMB, incremental net monetary benefit; ICUR, incremental cost utility ratio; NDVH, Non-descent vaginal hysterectomy; QALYs, Quality-adjusted life years; Q3, third quartile; RCT, randomized controlled trial; TLH, total laparoscopic hysterectomy; TAH, total abdominal hysterectomy; WTP, willingness to pay.

\section{Declarations}

\section{Trial status}

The first patient was randomised to the trial on August $1^{\text {st }}$ 2016. The trial concluded with the last participant follow-up on October $31^{\text {st }} 2018$.

\section{Ethics approval and consent to participate}

Ethical approval was obtained from the ethical review committee of the Faculty of Medicine, University of Kelaniya (P/12/01/2016). Informed written consent to participate was obtained from all participants.

\section{Consent for publication}

Not applicable.

\section{Availability of data and materials}

All data generated or analysed for this article are included in additional files 3, 4, 5, 6 and 7 .

\section{Competing interests}

The authors declare that they have no competing interests.

\section{Funding}

This study was funded by the National Research Council of Sri Lanka (NRC Grant no. 16-086).

\section{Authors' contributions}

$\mathrm{CE}$ is the principal investigator of the Study. CE, PW and AP designed the trial. CE, PW, AP and RH contributed to the funding application. PW is the grant holder. AP provided statistical expertise. SK provided expertise on economic evaluation. All authors read and reviewed study documents, participated in the preparation of the manuscript, and read and approved the final manuscript.

\section{Acknowledgements}

We are grateful to our sponsors; the study participants; staff of the two respective units; Dr. SR Jude, Regional Director of Health Services, Mannar, Sri Lanka; Dr. Rajini A Sisil, Director, District General 
Hospital, Mannar, Sri Lanka; and Dr. Roy Perera, Director, North Colombo Teaching Hospital, Ragama, Sri Lanka. A special note of appreciation goes to the research assistants; Dr. Rienzie Pieris, Dr. Suharshi Perera, Dr. Lakshika Liyanage, Dr. Malithi Kulasinghe and Dr. Sakshara Ranasinghe.

\section{References}

1. Whiteman, M K, Hillis SD, Jamieson, DJ, Morrow B, Podgornik MN, Brett KM, et al. Inpatient hysterectomy surveillance in the United States, 2000-2004: Commentary. Am J Obstet Gynecol. 2008;198(34):e1-7.

2. Hammer A, Rositch AF, Kahlert J, Gravitt PE, Blaakaer J, Søgaard M. Global epidemiology of hysterectomy: possible impact on gynecological cancer rates. Am J Obstet Gynecol [Internet]. Elsevier Inc.; 2015;213(1):23-9. Available from: http://dx.doi.org/10.1016/j.ajog.2015.02.019

3. Vessey MP, Villard-Mackintosh L, McPherson K, Coulter A, Yeates D. The epidemiology of hysterectomy: findings in a large cohort study. Br J Obs Gynaecol [Internet]. 1992;99(5):402-7. Available from: http://www.ncbi.nlm.nih.gov/pubmed/1622913

4. Ekanayake C, Pathmeswaran A, Kularatna S, Herath R, Wijesinghe P. Cost evaluation, quality of life and pelvic organ function of three approaches to hysterectomy for benign uterine conditions: Study protocol for a randomized controlled trial. Trials. Trials; 2017;18(1):1-10.

5. Nieboer TE, Johnson N, Lethaby A, Tavender E, Curr E, Garry R, et al. Surgical approach to hysterectomy for benign gynaecological disease. Cochrane Database Syst Rev. 2009;(3):2009-11.

6. Hiran Chaminda SH, Ekanayake C, Sriskanthan RS, Perera B, Palihawadana TS. Outcome of NonDescent Vaginal Hysterectomy at a Single Centre in Sri Lanka: an Observational Study. 2015; (September):42-6.

7. Balakrishnan D, Dibyajyoti G. A comparison between non-descent vaginal hysterectomy and total abdominal hysterectomy. J Clin Diagnostic Res. 2016;10(1):QC11-QC14.

8. Abrol S, Rashid S, Jabeen F, Kaul S. Comparative analysis of non-descent vaginal hysterectomy versus total abdominal hysterectomy in benign uterine disorders. Int J Reprod Contraception, Obstet Gynecol [Internet]. 2017;6(3):846. Available from: http://www.ijrcog.org/index.php/ijrcog/article/view/1641

9. Zwarenstein M, Treweek S, Gagnier JJ, Altman DG, Tunis S, Haynes B et al. Improving the reporting of pragmatic trials: an extension of the CONSORT statement. BMJ 337. 2008;337:a2390.

10. Husereau D, Drummond M, Petrou S, Carswell C, Moher D, Greenberg D, et al. CHEERS: Consolidated Health Economic Evaluation Reporting \nStandards. Eur J Heal Econ. 2013;14(3):367-72.

11. Einarsson JI, Suzuki Y. Total laparoscopic hysterectomy: 10 steps toward a successful procedure. Rev Obstet Gynecol. 2009;2(1):57-64.

12. Lopes T, Spirtos N, Naik R MJ. Operations on the Uterus. In: Bonney's Gynaecological Surgery. 11th ed. New Delhi: Wiley-Blackwell; 2010. p. 105-18. 
13. Ottosen $C$, Lingman G, Ottosen L. Three methods for hysterectomy: a randomised, prospective study of short term outcome. BJOG. 2000;107(11):1380-5. Available from:

http://www.ncbi.nlm.nih.gov/pubmed/11117766

14. EuroQol Group. EuroQol-a new facility for the measurement of health-related quality of life. Health Policy (New York). 1990;16(3):199-208.

15. Kularatna S, Whitty JA, Johnson NW, Jayasinghe R, Scuffham P a. EQ-5D-3L Derived Population Norms for Health Related Quality of Life in Sri Lanka. PLoS One [Internet]. 2014;9(11):e108434. Available from: http://dx.plos.org/10.1371/journal.pone.0108434

16. Ekanayake $C$, Pathmeswaran A, Kularatna S, Herath R, Wijesinghe P. Challenges of Costing a Surgical Procedure in a Lower-Middle-Income Country. World J Surg. 2018;

17. Woods B, Revill P, Sculpher M, Claxton K. Country-Level Cost-Effectiveness Thresholds: Initial Estimates and the Need for Further Research. Value Heal [Internet]. Elsevier; 2016;19(8):929-35. Available from: http://dx.doi.org/10.1016/j.jval.2016.02.017

18. Department of Census \& Statistics. Economic Statistics of Sri Lanka 2018. 2018;1-56. Available from: http://www.statistics.gov.lk/EconomicStat/EconomicStatistics2018.pdf

19. M.F. Drummond, Sculpher MJ, Torrance GW, O'Brien BJ and Stoddart GL. Methods for the economic evaluation of health care programme. Third edition. Third edit. Oxford: Oxford University Press; 2005.

20. Commission of Macroeconomics and Health. Macroeconomics and health: investing in health for economic development. Rev Panam Salud Pública. 2002;12(December):143-4.

21. Thavorncharoensap M, Teerawattananon $Y$, Natanant S, Kulpeng W, Yothasamut J, Werayingyong $P$. Estimating the willingness to pay for a quality-adjusted life year in Thailand: Does the context of health gain matter? Clin Outcomes Res. 2013;5(1):29-36.

22. Parliment of the Democratic Socialist Republic of Sri Lanka. No Title. No. 03 Sri Lanka: The Department of Government Printing; 2016 p. 1-12.

23. Gray AM, Clarke PM, Wolstenholme J WS. Applied Methods of Cost-effectiveness Analysis in Health Care. Oxford: Oxford University Press; 2011.

24. Petrou S, Gray A. Economic evaluation using decision analytical modelling: Design, conduct, analysis, and reporting. BMJ. 2011;342(7808):1-6.

25. Lewis J, Machin D. Intention to treat - who should use ITT? Br J Cancer [Internet]. 1993;68(4):64750. Available from: http://www.nature.com/doifinder/10.1038/bjc.1993.402

26. Salsburg D. Intent to treat: The reductio ad absurdum that became gospel. Pharmacoepidemiol Drug Saf. 1994;3(6):329-35.

\section{Tables}

Table 1 Basic characteristics 


\begin{tabular}{lcccc}
\hline & TAH $(\mathrm{n}=49)$ & NDVH $(\mathrm{n}=49)$ & TLH $(\mathrm{n}=49)$ & $\mathrm{p}$ value \\
\hline Age [mean, (95\% CI)] & $47.0(45.6-48.4)$ & $47.1(44.8-49.5)$ & $48.1(46.2-50.1)$ & $0.63^{\#}$ \\
BMI [kg/m² (95\% CI)] & $26.4(24.8-28.0)$ & $25.7(24.2-27.1)$ & $25.0(23.3-26.7)$ & $0.51^{\#}$ \\
Median parity (Q1-Q3) & $2(2-3)$ & $3(2-3.5)$ & $3(2-3.5)$ & $0.20^{*}$ \\
Uterine weight (g) & $124(90-252)$ & $111(91-153)$ & $141(101-199)$ & $0.16^{*}$ \\
[median (Q1-Q3) $]$ & & & & \\
\hline
\end{tabular}

\# - One-way ANOVA

*- Kruskal Wallis test

Table 2 Clinical Outcomes\# 


\begin{tabular}{|c|c|c|c|c|}
\hline & TAH $(\mathrm{n}=49)$ & NDVH $(n=49)$ & TLH $(\mathrm{n}=49)$ & $\mathrm{p}$ value* \\
\hline Anaesthetic time (min) & $85(65-100)$ & $75(64-100)$ & $135(116-152)$ & $<0.001$ \\
\hline Operative time (min) & $45(36.5-60)$ & $50(35-65)$ & $93(80-111)$ & $<0.001$ \\
\hline Post-operative hospital stay (days) & $3(2-3)$ & $3(2-3)$ & $2(1-3)$ & $<0.001$ \\
\hline Blood loss (ml) & $150(100-200)$ & $150(100-275)$ & $150(100-300)$ & 0.51 \\
\hline Change in haematocrit & $1.8(0.78-3.8)$ & $2.7(1.2-5.1)$ & $1.9(1-3.2)$ & 0.30 \\
\hline Pain score - Day 1 & $7(5.5-8.2)$ & $6(5-7)$ & $5(4-6.8)$ & $<0.01$ \\
\hline Pain score - Day 2 & $4(3-5.5)$ & $3(2-4.7)$ & $3(1-4)$ & $<0.01$ \\
\hline Pain score - Day 3 & $1.2(0-4)$ & $1(0-2)$ & $0(0-2)$ & 0.14 \\
\hline Time to recover (median, Q1-Q3) (days) & $35(30-45)$ & $32(24.5-60)$ & $30(25.5-45)$ & 0.37 \\
\hline \multicolumn{5}{|l|}{ Complications $\square$} \\
\hline No complications & 42 & 41 & 37 & \\
\hline Laparotomy & 0 & 3 & 2 & \\
\hline Blood transfusion & 5 & 6 & 5 & \\
\hline Bladder injury & 0 & 2 & 0 & \\
\hline Ureteric injury & 0 & 0 & 1 & \\
\hline Rectal injury & 0 & 1 & 0 & \\
\hline Post-operative fever & 2 & 0 & 2 & \\
\hline Skin wound infection & 1 & 1 & 0 & \\
\hline Urinary tract infection & 0 & 0 & 2 & \\
\hline \multicolumn{5}{|l|}{ Histology } \\
\hline -Leiomyoma & 20 & 12 & 13 & \\
\hline -Adenomyosis & 06 & 10 & 09 & \\
\hline -Leiomyoma and adenomyosis & 06 & 06 & 05 & \\
\hline \multicolumn{5}{|l|}{-Proliferative/secretory endometrium } \\
\hline \multirow[t]{2}{*}{-Other } & 07 & 11 & 17 & \\
\hline & 10 & 10 & 05 & \\
\hline
\end{tabular}

\#-median (Q1-Q3) 
*- Kruskal Wallis test [- Patients can have one or more complication

Table 3 Costs and effects of TAH, NDVH and TLH

-median (interquartile range) are reported

$\alpha_{-(\text {mean, } 95 \% \mathrm{CI})}$

-values reported to the nearest USD value using conversion of 1 USD=144.9625 (01/01/2017)

\begin{tabular}{|c|c|c|c|c|}
\hline & TAH $(n=49)$ & NDVH $(n=49)$ & TLH $(\mathrm{n}=49)$ & $\mathrm{p}$ value \\
\hline Time to recover (days) & $35(30-45)$ & $32(24.5-60)$ & $30(25.5-45)$ & 0.37 \\
\hline QALYs AUC & 8.63 & 9.97 & 13.84 & \\
\hline Direct costs & $\begin{array}{c}289 \\
(264-307)\end{array}$ & $\begin{array}{c}279 \\
(255-305)\end{array}$ & $\begin{array}{c}349 \\
(322-378)\end{array}$ & $<0.001$ \\
\hline Direct costs (mean) ${ }^{\alpha}$ & $\begin{array}{c}293 \\
(283-304)\end{array}$ & $\begin{array}{c}343 \\
(232-455)\end{array}$ & $\begin{array}{c}353 \\
(338-368)\end{array}$ & $<0.001$ \\
\hline Indirect costs & $\begin{array}{c}48 \\
(20-98)\end{array}$ & $\begin{array}{c}51 \\
(20-135)\end{array}$ & $\begin{array}{c}48 \\
(25-122)\end{array}$ & 0.90 \\
\hline Total costs & $\begin{array}{c}338 \\
(310-408)\end{array}$ & $\begin{array}{c}334 \\
(297-414)\end{array}$ & $\begin{array}{c}412 \\
(364-460)\end{array}$ & $<0.001$ \\
\hline Worst case scenario ${ }^{\#}$ & $\begin{array}{c}931 \\
(854-1069)\end{array}$ & $\begin{array}{c}870 \\
(765-1218)\end{array}$ & $\begin{array}{c}994 \\
(892-1266)\end{array}$ & 0.06 \\
\hline Worst case scenario $^{\#}$ (mean, 95\% CI) & $\begin{array}{c}1018 \\
(925-1111)\end{array}$ & $\begin{array}{c}1108 \\
(837-1380)\end{array}$ & $\begin{array}{c}1130 \\
(996-1264)\end{array}$ & 0.06 \\
\hline Best case scenario ${ }^{\square}$ & $\begin{array}{c}766 \\
(682-886)\end{array}$ & $\begin{array}{c}710 \\
(607-1052)\end{array}$ & $\begin{array}{c}844 \\
(743-1100)\end{array}$ & 0.03 \\
\hline Best case scenario (mean, 95\% CI) & $\begin{array}{c}847 \\
(755-938)\end{array}$ & $\begin{array}{c}872 \\
(729-1015)\end{array}$ & $\begin{array}{c}962 \\
(847-1078)\end{array}$ & 0.03 \\
\hline
\end{tabular}

\# - discounting 10\%, 5-year shelf life for instruments, worst-case scenario, 1500 per day till convalescence is complete 
$\square$ - discounting 10\%, 5-year shelf life for instruments, best case scenario, 1500 per day till convalescence is complete

AUC-area under curve, NDVH - non descent vaginal hysterectomy, QALY-quality adjusted life years, TAH-total abdominal hysterectomy, TLH-total laparoscopic hysterectomy

口- costs were published earlier (16)

Table 4 Economic evaluation comparing NDVH and TLH to TAH 


\begin{tabular}{|c|c|c|c|c|}
\hline & $\begin{array}{c}\text { TAH } \\
(n=49)\end{array}$ & $\mathrm{NDVH}(\mathrm{n}=49)$ & $\begin{array}{c}\text { TLH } \\
(\mathrm{n}=49)\end{array}$ & $\begin{array}{c}\mathrm{p} \\
\text { value* }\end{array}$ \\
\hline Incremental effect & $\begin{array}{c}0 \\
(-5 \text { to } 10)\end{array}$ & $\begin{array}{c}-3 \\
(-10.5 \text { to } 25)\end{array}$ & $\begin{array}{c}-5 \\
(-9.5 \text { to } 10)\end{array}$ & 0.37 \\
\hline Incremental difference in QALYs AUC* & 0 & 1.33 & 5.21 & \\
\hline Incremental direct cost from study & $\begin{array}{c}0 \\
(-25 \text { to } 17)\end{array}$ & $\begin{array}{c}-11 \\
(-35 \text { to } 16)\end{array}$ & $\begin{array}{c}60 \\
(33-89)\end{array}$ & $<0.001$ \\
\hline $\begin{array}{l}\text { Incremental direct cost from study (using TAH } \\
\text { mean) }\end{array}$ & $\begin{array}{c}0 \\
(-11 \text { to } 11)\end{array}$ & $\begin{array}{c}50 \\
(-62 \text { to } 162)\end{array}$ & $\begin{array}{c}60 \\
(45-75)\end{array}$ & $<0.001$ \\
\hline Incremental direct costs (worst-case scenario) & $\begin{array}{c}0 \\
(-21 \text { to } 28)\end{array}$ & $\begin{array}{c}-18 \\
(-48 \text { to } 13)\end{array}$ & $\begin{array}{c}117 \\
(78-169)\end{array}$ & 0.06 \\
\hline Incremental direct costs (worst-case scenario) \# & $\begin{array}{c}0 \\
(-93 \text { to } 93)\end{array}$ & $\begin{array}{c}90 \\
(-182 \text { to } 362)\end{array}$ & $\begin{array}{c}112 \\
(-22 \text { to } \\
246)\end{array}$ & 0.06 \\
\hline $\begin{array}{l}\text { Incremental direct costs } \\
\text { (best case scenario) }\end{array}$ & $\begin{array}{c}0 \\
(-19 \text { to } 20)\end{array}$ & $\begin{array}{c}-18 \\
(-46 \text { to } 13)\end{array}$ & $\begin{array}{c}120 \\
(91-162)\end{array}$ & 0.03 \\
\hline $\begin{array}{l}\text { Incremental direct costs } \\
\text { (best case scenario) }^{\#}\end{array}$ & $\begin{array}{c}0 \\
(-91 \text { to } 91)\end{array}$ & $\begin{array}{c}25 \\
(-118 \text { to } 168)\end{array}$ & $\begin{array}{c}115 \\
(0 \text { to } 231)\end{array}$ & 0.03 \\
\hline ICER-Study (USD/day) & 0 & $\begin{array}{c}\text { NDVH } \\
\text { dominates }\end{array}$ & 12 & \\
\hline ICER (worst case scenario) (USD./day) & 0 & TAH dominates & $\alpha$ & \\
\hline ICER (best case scenario) (USD./day) & 0 & $\begin{array}{c}\text { NDVH } \\
\text { dominates }\end{array}$ & 24 & \\
\hline ICUR using QALYs (USD./QALY) & 0 & 38 & 12 & \\
\hline ICUR using QALYs - worst case ${ }^{\alpha}$ (USD./QALY) & 0 & 68 & 21 & \\
\hline ICUR using QALYs - best case ${ }^{\beta}$ (USD./QALY) & & 19 & 22 & \\
\hline ICUR using QALYs (TLH-NDVH) (USD./QALY) & & & 03 & \\
\hline NMB (study) & 0 & 1264 & 4897 & \\
\hline NMB (worst case scenario) & 0 & 1210 & 4626 & \\
\hline
\end{tabular}


-median (interquartile range) reported for incremental effect and costs in relation to TAH

-values reported to the nearest USD value using conversion of 1 USD = SL Rs. $144.9625(01 / 01 / 2017)$

*-Kruskal-Wallis test

\#-mean, 95\% CI values reported in relation to TAH

${ }^{\alpha}$-using upper limit of $95 \%$ CI value

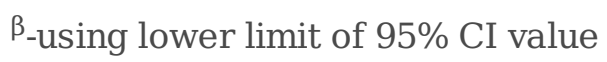

AUC-area under curve, ICER- Study - incremental cost-effectiveness ratio, ICUR- incremental cost utility ratio, NDVH - non descent vaginal hysterectomy, NMB- net monetary benefit, QALY-quality adjusted life years, TAHtotal abdominal hysterectomy, TLH-total laparoscopic hysterectomy

\section{Figures}




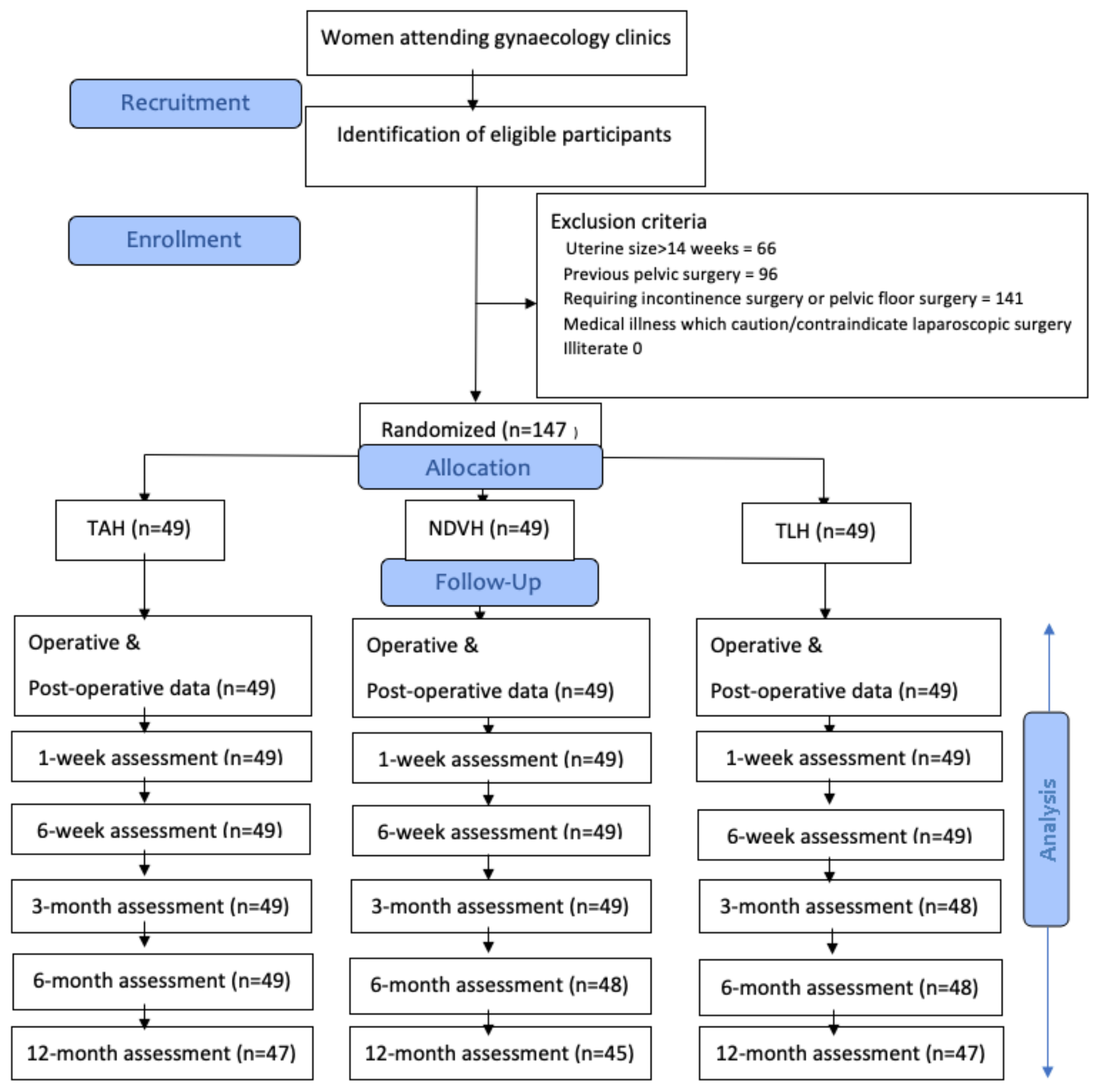

Figure 1

CONSORT flow diagram. 


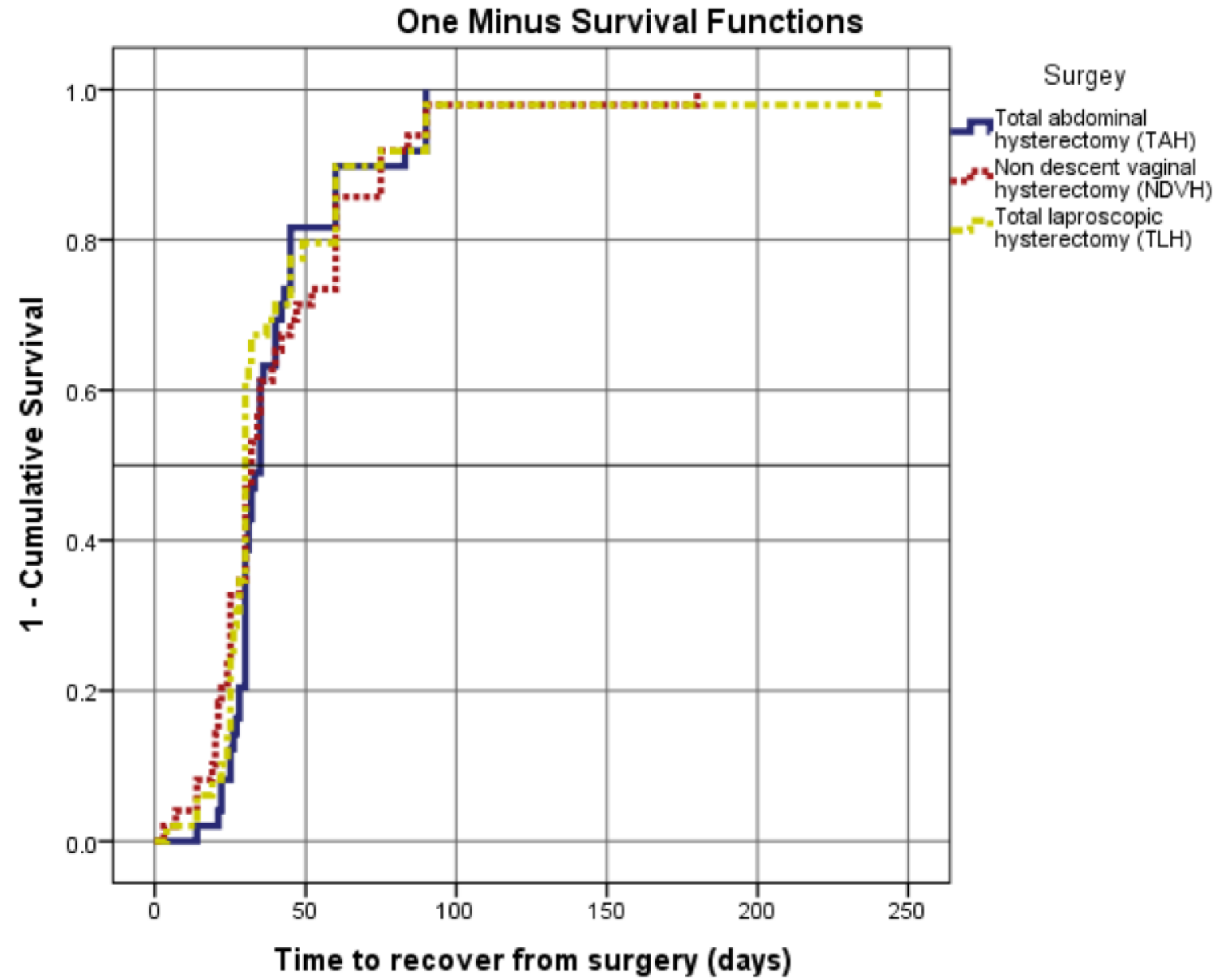

Figure 2

Kaplan-Meier survival analysis.

\section{Supplementary Files}

This is a list of supplementary files associated with this preprint. Click to download.

- Additionalfile5Coxregressionforanalysisofcovariates.docx

- Additionalfile1CONSORTChecklist.doc

- Additionalfile4Database.sav

- Additionalfile3Statisticalanalysisplan.docx

- Additionalfile6ChangeinutilityscoresFig.docx

- Additionalfile2CHEERSchecklist.DOC 